Archived version from NCDOCKS Institutional Repository http://libres.uncg.edu/ir/asu/

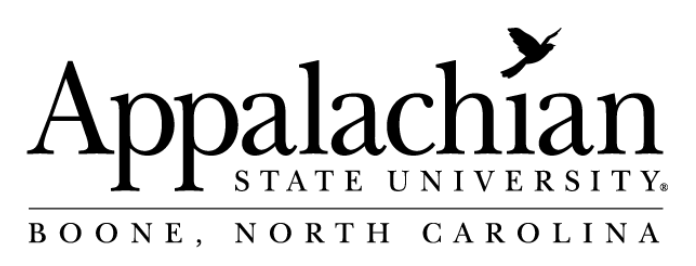

\title{
Self-Interest, Sympathy And The Origin Of Endowments
}

\author{
By: Todd L. Cherry \& Jason F. Shogren
}

\begin{abstract}
We explore whether the recent laboratory findings that suggest the origin of endowment matters in simple bargaining games are actually due to contextual shifts of relative effort and deservingness. Results support previous findings of endowment origin yielding more self-interested behavior.
\end{abstract}

Todd L. Cherry \& Jason F. Shogren (2008) "Self-Interest, Sympathy And The Origin Of Endowments" Economic Letters Volume 101 Issue 1 pp. 69-72

[ DOI: 10.1016/j.econlet.2008.04.007] Version of Record Available From (www.sciencedirect.com) 


\section{Introduction}

During the last decade, economists have explored the nature of social preferences-self-interested people who are also concerned about the payoffs and intentions of others (see for example Charness and Rabin, 2002; Camerer and Fehr, 2004). Such "other-regarding behavior" is observed in many bargaining games such as the Anonymous Dictator game (see Hoffman et al., 1994). This game explores the nature of self-interested strategic behavior by giving a person complete control over the distribution of endowed money, and complete anonymity from all others including the experimenter. Theory predicts rational dictators with complete control and complete anonymity will offer up nothing to others; evidence suggests otherwise-dictators frequently share the endowment. These social preferences illustrate how a person's behavior differs from that predicted by rational choice, and supports the call for a new behavioral game theory based on a broader set of social preferences such as aversion to unequal distributions of wealth (e.g., Camerer, 2003).

In response, Cherry et al. (2002) extended the Anonymous Dictator game to create an institutional context in which nearly all dictators were hardnosed rational game-theorists-9.5 of every 10 dictators gave nothing to their subordinates. Their straightforward adjustment to the experimental design had dictators make offers based on earned endowments rather than windfall endowments. ${ }^{2}$ Legitimizing money with effort, along with social isolation, appears to close the gap between observation and standard game theory. ${ }^{3}$

But dictators earning the endowments inherently alters the symmetry of effort and possibly the perceived relative deservingness of the players, which previous work argues may influence dictator offers (Eckel and Grossman, 1996; Charness and Rabin, 2002). So one may suggest the observed earned endowment effect is really due to changes in relative deservingness, not legitimizing the endowment with effort. Herein we disentangle these two factors by testing the effect of earning endowments across three contexts that alter the deservingness of the recipient. Results provide evidence that recipient deservingness matters, though it does not explain the previously

is We thank Bart Wilson and his students at George Mason University for motivating this study. Timothy Perri, Mark Strazicich and Stephan Kroll provided helpful comments. Support from the Walker College of Business at Appalachian State University is greatly appreciated.

2 Oxoby and Spraggon (2008) report even stronger results in a subsequent study. In their experiments, dictators that earned their endowment offered nothing to their subordinates in all cases.

${ }^{3}$ This finding follows previous work that indicated effort and deservingness matter in simple bargaining games; see for example Kahneman et al. (1986), Shogren (1989), Ruffle (1998) and Konow (2000). 


\begin{tabular}{|c|c|c|c|c|c|c|}
\hline & \multicolumn{3}{|c|}{ Windfall endowment } & \multicolumn{3}{|c|}{ Earned endowment } \\
\hline & No opportunity & Neutral & Opted out of opportunity & No opportunity & Neutral & Opted out of opportunity \\
\hline \multicolumn{7}{|l|}{ Mean offer } \\
\hline Endow $=\$ 10$ & $\begin{array}{c}\$ 3.47 \\
(34.7 \%)\end{array}$ & $\begin{array}{c}\$ 2.41 \\
(24.1 \%)\end{array}$ & $\begin{array}{c}\$ 1.12 \\
(11.1 \%)\end{array}$ & $\begin{array}{c}\$ 2.41 \\
(24.1 \%)\end{array}$ & $\begin{array}{l}\$ 0.77 \\
(7.7 \%)\end{array}$ & $\begin{array}{l}\$ 0.00 \\
(0.0 \%)\end{array}$ \\
\hline Endow $=\$ 20$ & $\begin{array}{c}\$ 7.18 \\
(35.9 \%)\end{array}$ & $\begin{array}{c}\$ 6.18 \\
(30.9 \%)\end{array}$ & $\begin{array}{c}\$ 2.41 \\
(12.1 \%)\end{array}$ & $\begin{array}{c}\$ 6.65 \\
(33.2 \%)\end{array}$ & $\begin{array}{l}\$ 1.00 \\
(5.0 \%)\end{array}$ & $\begin{array}{l}\$ 0.12 \\
(0.6 \%)\end{array}$ \\
\hline \multicolumn{7}{|l|}{ Positive offers } \\
\hline Endow $=\$ 10$ & $\begin{array}{c}14 \\
(88.2 \%)\end{array}$ & $\begin{array}{c}12 \\
(70.6 \%)\end{array}$ & $\begin{array}{c}8 \\
(47.1 \%)\end{array}$ & $\begin{array}{c}12 \\
(79.4 \%)\end{array}$ & $\begin{array}{c}5 \\
(26.5 \%)\end{array}$ & $\begin{array}{c}0 \\
(0.0 \%)\end{array}$ \\
\hline Endow $=\$ 20$ & $\begin{array}{c}16 \\
(88.2 \%)\end{array}$ & $\begin{array}{c}14 \\
(82.45 \%)\end{array}$ & $\begin{array}{c}7 \\
(41.2 \%)\end{array}$ & $\begin{array}{c}15 \\
(79.4 \%)\end{array}$ & $\begin{array}{c}4 \\
(26.5 \%)\end{array}$ & $\begin{array}{c}2 \\
(11.8 \%)\end{array}$ \\
\hline \multicolumn{7}{|l|}{ Equal splits } \\
\hline Endow $=\$ 10$ & $\begin{array}{c}7 \\
(35.3 \%)\end{array}$ & $\begin{array}{c}3 \\
(17.7 \%)\end{array}$ & $\begin{array}{c}1 \\
(5.9 \%)\end{array}$ & $\begin{array}{c}4 \\
(23.5 \%)\end{array}$ & $\begin{array}{c}1 \\
(2.9 \%)\end{array}$ & $\begin{array}{c}0 \\
(0.0 \%)\end{array}$ \\
\hline Endow $=\$ 20$ & $\begin{array}{c}5 \\
(35.3 \%)\end{array}$ & $\begin{array}{c}4 \\
(23.5 \%)\end{array}$ & $\begin{array}{c}2 \\
(5.9 \%)\end{array}$ & $\begin{array}{c}4 \\
(23.5 \%)\end{array}$ & $\begin{array}{c}0 \\
(2.9 \%)\end{array}$ & $\begin{array}{c}0 \\
(0.0 \%)\end{array}$ \\
\hline$N$ & 34 & 34 & 34 & 34 & 34 & 34 \\
\hline
\end{tabular}

Notes: Figures in parentheses are the percentages of total endowment or total bargains.

reported earn endowment effect. Dictators can be sympathetic, but less so with earned money.

\section{The experiment}

The basic experimental design follows previous work (Oxoby and Spraggon, 2008 and Cherry et al., 2002). ${ }^{4}$ When recruited, subjects were assigned to group A or B, with each group meeting in separate rooms at separate times. The two groups did not have any contact before, during, or after the session. Subjects were randomly matched across groups to form bargaining pairs. Instructions for the dictator game were read aloud to both groups, and all questions were addressed. Person A was the first mover (i.e., the dictator) and dictated a split of his or her endowment with Person B (i.e., the recipient). Administrators delivered the offers to recipients. All bargains were one-shot, and players had complete information. Final earnings were determined, and subjects departed individually with cash payment.

Our experiment follows a $2 \times 3$ design that varies two factors of the basic framework: endowment origin; (1) earned or (2) windfall, and recipient opportunity; (a) had no opportunity to earn or receive any money, (b) had an opportunity, but opted out, or (c) neutral-the classic treatment in which no information is disclosed about recipient's opportunity. ${ }^{5}$ Two hundred and eight students from the undergraduate student body at Appalachian State University participated in the six sessions, each session having 34 independent bargaining pairs. ${ }^{6}$

\subsection{Endowment}

In the earned endowment treatments, dictators earned money by answering 17 questions taken from the Graduate Management Admissions Test (GMAT). We ranked people based on the number of correct answers; ties were broken by the amount of time taken to answer the questions. Those performing in the top half of the group earned $\$ 20$, while those in the bottom half earned \$10. Dictators acted over their earnings in the bargain.

\footnotetext{
4 The protocol for subject anonymity follows Oxoby and Spraggon (2008), which is a weaker form of the double-blind protocol demonstrated in Hoffman et al. (1996) and Cherry et al. (2002).

${ }^{5}$ Our primary focus is on the no opportunity versus opted out of opportunity conditions. But additional categories of deservingness exist and are worth exploring in future research, e.g., recipient who was given an opportunity to earn wealth and actually took the opportunity.

${ }^{6}$ Sessions followed a written protocol to ensure consistency.
}

The windfall treatments followed the standard protocol of the experimenter allocating money to the dictators. To mimic the earned endowment treatment, half of the dictators were randomly selected to receive $\$ 10$, with the other half receiving $\$ 20$. Dictators subsequently acted over their allocated endowments in the bargain. ${ }^{7}$

\subsection{Knowledge of recipient opportunity}

We considered three contextual variations of recipient opportunities to earn or receive endowments themselves: no opportunity, opted out of opportunity, and neutral. In the no opportunity treatment, dictators were informed the recipient in Room B had no opportunity to earn or receive money. The recipient only received what the dictator offered. In the opted out of opportunity treatment, dictators knew recipients had an opportunity to earn or receive money, but choose not to participate. Dictators were randomly assigned to people that were recruited for the experiment but chose not to participate. Therefore, unlike other treatments, recipients in the 'opted out' treatment were not in Room B and received their payoffs (if any) at a later date. ${ }^{8}$ The neutral treatment did not provide the dictators any information about the recipient's opportunity to earn or receive money-neither having nor not having an opportunity.

\section{Experimental results}

Table 1 reports the aggregate results by treatment and endowment level. Results confirm previous reports that dictators make significantly lower offers when acting over earned rather than windfall endowment (e.g., Oxoby and Spraggon, 2008; Cherry et al., 2002). Across the treatments, dictators acting over earned endowments offered less than those acting over windfall endowments in all cases. In the low endowment bargains, dictators that earned their endowment offered $\$ 1.06$ (31\%) less in the no opportunity treatment, \$1.64 (68\%) less in the neutral treatment, and $\$ 1.12(100 \%)$ less in the opted out treatment. Dictators that earned high endowments offered $\$ 0.53$ (7\%)

\footnotetext{
7 The selection of high and low endowment dictators in the earned and windfall treatments differ (exam score versus random), which may raise questions of sample selection, but previous research using this selection method has found this is not a significant concern.

${ }^{8}$ The instructions stated the recipient "decided not to participate" in the session. Instructions are available upon request.
} 
Table 2

Estimates of treatment effects

\begin{tabular}{lcc}
\hline & Basic model & Expanded model \\
\hline Constant & $0.2211^{* * * *}$ & $0.2618^{* * *}$ \\
No opportunity & $(9.16)$ & $(9.30)$ \\
& $0.1507^{* * *}$ & $0.0779^{* *}$ \\
Opted out & $(5.70)$ & $(2.12)$ \\
& $-0.1096^{* * *}$ & $-0.1588^{* * *}$ \\
\$20 endowment & $(-4.14)$ & $(-4.31)$ \\
& 0.0265 & 0.0265 \\
Earned & $(1.23)$ & $(1.24)$ \\
& $-0.1304^{* * *}$ & $-0.2118^{* * *}$ \\
Earned $*$ no opportunity & $(-6.04)$ & $(-5.75)$ \\
& - & $0.1456^{* * *}$ \\
Earned $*$ opted out & - & $(2.79)$ \\
& & $0.0985^{*}$ \\
$F$ & $(p$-value) & $(1.89)$ \\
$N$ & 33.90 & 24.65 \\
& $(0.0000)$ & $(0.0000)$ \\
\end{tabular}

Notes: Dependent variable is the percent of endowment offered. $t$-statistics reported in parentheses unless noted otherwise.

$*, * *$ and $* * *$ indicate statistical significance at the 10,5 and $1 \%$ levels.

less in the no opportunity treatment, $\$ 5.18(84 \%)$ in the neutral treatment, and $\$ 2.29$ (95\%) less in the opted out treatment. ${ }^{9}$

Aggregate numbers indicate that dictators acting over earned endowments adhered closely to the theoretically predicted behavior of zero offers in the neutral and opted out treatments, but even with an earned endowment, they exhibit sympathy to subordinates in the no opportunity treatment. The other measures reported in Table 1 further illustrate these findings-the number of positive offers and equal splits was lower in all cases when dictators acted over earned endowments rather than windfall endowments, but less so in the no opportunity treatment.

The aggregate numbers also indicate recipient opportunity matters, regardless of the endowment origin. Whether the endowment was earned or not, dictators offered more to recipients that had no opportunity to earn or receive money, and offered less to those that opted out of opportunities. There were also more positive offers, more equal splits, and higher average offers when recipients had no opportunity, and the converse was true when recipients opted out of opportunities. This result is consistent with previous work showing dictators acting over allocated endowments offer more to charities and those living in poverty (Brañas-Garza, 2006; Eckel and Grossman, 1996), but herein we show such contextual influences are robust across earned and windfall endowments. Interestingly, the numbers reveal a larger difference between earned and windfall offers in the neutral treatment relative to the other treatments. This raises questions for future research concerning the beliefs of dictators in the absence of recipient information, and whether the lack of context leads to self-serving biases or presumptions that recipients are like them (Babcock and Loewenstein, 1997).

We reinforce these preliminary aggregate observations by undertaking an individual-level conditional analysis with the following model:

$O_{i}=\alpha+\phi \mathrm{Opp}_{i}+\omega \mathrm{Earn}_{i}+\theta \mathrm{Endow}_{i}+\psi \mathrm{Earn}^{*} \mathrm{Opp}_{i}+\varepsilon_{i}$,

where $O_{i}$ is the offer by the $i$ th dictator as a percent of her endowment, $\mathrm{Opp}_{i}$ is a vector of binary variables signifying the opportunity of the $i$ th dictator's recipient (neutral omitted), $\operatorname{Earn}_{i}$ is a single dichotomous variable that equals 1 if the ith dictator earned her endowment, 0 otherwise; Endow $i$ is a dichotomous variable indicating the $i$ th

\footnotetext{
${ }^{9}$ We note that, as a reviewer points out, since endowments were earned via a quiz, there is a possibility that the process of earning wealth confounds with the wealth being earned.
}

dictator's endowment level ( 1 if $\$ 20,0$ otherwise); Earn* $0 p_{i}$ is a vector of interaction variables that capture the relative impact of an endowment being earned across recipient opportunities; $\alpha$ is the estimated intercept, and $\varepsilon_{i}$ is the error term. We estimate a basic and full model, which differ by the inclusion of the interaction variables.

Table 2 reports the parameter estimates and confirms our initial impressions. Both the origin of endowment and recipient opportunity matters. Estimates across both the basic and full models show dictators bargaining with an earned endowment offered significantly less money than those acting over allocated money-even when controlling for recipient opportunity. Results therefore indicate the observed earned endowment effect is not just an artifact of contextual nuances; rather it arises because endowments are earned rather than allocated.

Results also indicate dictators offered significantly more to recipients that had no opportunity to earn or receive money relative to the neutral baseline, and they offered less to recipients that opted out of an opportunity. The robustness of this result is illustrated by estimated coefficients of the expanded model, which reveals sympathetic offers arose regardless of the endowment origin. ${ }^{10}$

\section{Conclusions}

Recent bargaining experiments draw upon the notion of mental accounting to explore whether endowment origin matters in simple bargaining games (Thaler, 1990; Thaler, 1999). Results show that dictators acting over money they earned, rather than money they were allocated, adhered more closely to standard game theoretic predictions (Oxoby and Spraggon, 2008 and Cherry et al., 2002). Dictators earning endowments however also changes the relative effort within the bargain and potentially the relative perceived deservingness of the players. Some may wonder whether the reported earned endowment effect is due to changes in relative deservingness, not legitimizing the endowment. Results herein suggest this is not the case.

We find, as expected, recipient opportunity matters-dictators offered more to recipients that had no opportunity to earn or receive money, and less to those that opted out of such an opportunity. But we also find this did not explain away the earned endowment effect. We find, regardless of recipient opportunity, dictators offered significantly less when acting over earned endowments than windfall endowments. While dictators that earned their endowment exhibited hardnosed behavior in most cases, they did show sympathy to subordinates that had no opportunity; though significantly less with earned money.

In his plenary lecture at the 2007 Economic Science Association Meetings in Rome, Vernon Smith highlighted the implication of the earned endowment effect. In thinking about the next big questions in experimental economics, he wondered whether legitimizing endowments with effort would change other findings as well. We know a lot about how people spend other people's money in experiments; perhaps we should continue initial efforts to learn more about how they spend their own money (e.g., Clark, 2002; Cherry et al., 2005).

\section{References}

Babcock, L., Loewenstein, G., 1997. Explaining bargaining impasse: the role of selfserving biases. Journal of Economic Perspectives 11 (1), 109-126.

Brañas-Garza, P., 2006. Poverty in dictator games: awakening solidarity. Journal of Economic Behavior and Organization 60 (3), 306-320.

Camerer, C., 2003. Behavioral Game Theory. Experiments in Strategic Interaction. Princeton University Press, Princeton, New Jersey.

Camerer, C.F., Fehr, E., 2004. Measuring social norms and preferences using experimental games: a guide for social scientists. In: Henrich, J.P., Boyd, R., Bowles, S., Camerer, C.F., Fehr, E., Gintis, H. (Eds.), Foundations of Human Sociology-Economic

\footnotetext{
10 Given the two endowment levels ( $\$ 10$ and $\$ 20$ ) arising from the experimental design, results also add to the literature on the impact of stakes in simple bargaining games and find no significant difference in offers between $\$ 10$ versus $\$ 20$ bargains.
} 
Experiments and Ethnographic Evidence from 15 Small-scale Societies. Oxford University Press, New York, pp. 55-95.

Charness, G., Rabin, M., 2002. Understanding social-preferences with simple tests. Quarterly Journal of Economics 117, 817-869.

Cherry, T.L., Frykblom, P., Shogren, J.F., 2002. Hardnose the dictator. American Economic Review 92 (4), 1218-1221.

Cherry, T.L., Kroll, S., Shogren, J.F., 2005. The impact of endowment heterogeneity and origin on public good contributions: evidence from the lab. Journal of Economic Behavior and Organization 57 (3), 357-365.

Clark, J., 2002. House money effects in public good experiments. Experimental Economics 5, 223-231.

Eckel, C., Grossman, P., 1996. Altruism in anonymous dictator games. Games and Economic Behavior 16 (2), 181-191.

Hoffman, E., McCabe, K., Smith, V.L., 1994. Preferences, property rights, and anonymity in bargaining games. Games and Economic Behavior 7, 346-380.

Hoffman, E., McCabe, K., Smith, V.L., 1996. Social distance and other-regarding behavior in dictator games. American Economic Review 86 (3), 653-660.
Kahneman, D., Knetsch, J.L., Thaler, R.H., 1986. Fairness and the assumptions of economics. Journal of Business 59 (4), S285-S300.

Konow, J., 2000. Fair shares: accountability and cognitive dissonance in allocation decisions. American Economic Review 90 (4), 1072-1091.

Oxoby, R.J., Spraggon, J., 2008. Mine and Yours: Property Rights in Dictator Games. Journal of Economic Behavior and Organization 65 (3-4), 703-713.

Ruffle, B.J., 1998. More is better, but fair is fair: tipping in dictator and ultimatum games. Games and Economic Behavior 23 (2), 247-265.

Shogren, J.F., 1989. Fairness in bargaining requires a context: an experimental examination of loyalty. Economics Letters 31, 319-323.

Smith, V.L., 2007. Plenary Address, 2007 Economic Science Association Meetings, Rome Italy.

Thaler, R.H., 1990. Anomalies: savings, fungibility, and mental accounts. Journal of Economic Perspectives 4 (1), 193-205.

Thaler, R.H., 1999. Mental accounting matters. Journal of Behavioral Decision Making 12 (3), 183-206. 